\title{
Epidemiology of primary systemic vasculitis in the Australian Capital Territory and south-eastern New South Wales
}

\author{
A. S. Ormerod ${ }^{1}$ and M. C. Cook $^{2}$ \\ ${ }^{1}$ The Canberra Hospital and ${ }^{2}$ Department of Immunology, The Canberra Hospital, ANU Medical School, Australian National University, Canberra, \\ Australian Capital Territory, Australia
}

\section{Key words}

antineutrophil cytoplasmic antibody, epidemiology, Wegener's granulomatosis, polyarteritis, systemic vasculitis.

\section{Correspondence \\ Matthew C. Cook, Department of Immunology, The Canberra Hospital, PO Box 11, Woden, ACT 2606, Australia. \\ Email: matthew.cook@anu.edu.au}

Received 6 August 2007; accepted 17 February 2008.

doi:10.1111/j.1445-5994.2008.01672.x

\begin{abstract}
Background: The aim of the study was to determine the epidemiology of primary systemic vasculitis in the Australian Capital Territory and the surrounding rural region between 1995 and 2005.

Methods: Cases were ascertained by a medical record search according to international consensus classification criteria. For antineutrophil cytoplasmic antibody-associated vasculitides, ascertainment was corroborated by a search of all positive antineutrophil cytoplasmic antibody serology during the study period. Denominators were obtained from region-specific census data collected during the study period. Prevalence, incidence and patient characteristics for primary systemic vasculitides were determined for two 5-year periods, 1995-1999 and 2000-2004.

Results: We identified 41 cases of primary systemic vasculitides (Wegener's granulomatosis (WG), microscopic polyangiitis (MPA), Churg-Strauss syndrome or polyarteritis nodosa) between 1995 and 1999 and 67 between 2000 and 2004, giving prevalences of 95/million (95\% confidence interval (CI) 76.9116.1 ) and 148/million (95\%CI 125.1-173.9), respectively. Annual incidence was similar in both periods (approximately 17/year per million adult population). Disease-specific incidences (per million per year) for each of the two periods were 8.8 and 8.4 for WG, 2.3 and 5.0 for MPA, 2.3 and 2.2 for ChurgStrauss syndrome and 2.3 and 1.1 for polyarteritis nodosa. The rural incidence of MPA was 13.9 (95\% CI 7.7-23.5) compared with 1.6 (95\% CI 0.2-7.2) in the city and there was a trend towards a higher incidence of WG in rural than urban areas.

Conclusion: The overall incidence of primary systemic vasculitides is similar to that reported from other developed countries. WG is more common in southeastern Australia than in southern Europe, whereas MPA is less common. There was a trend towards higher incidence of antineutrophil cytoplasmic antibodyassociated vasculitides in rural than urban areas.
\end{abstract}

\section{Introduction}

The primary systemic vasculitides (PSV) are a heterogeneous group of inflammatory diseases of unknown aetiology. These are rare disorders that have potentially

Funding: None

Potential conflicts of interest: None devastating consequences because of vascular compromise and parenchymal inflammation in one or more organs. ${ }^{1,2}$ Distinct clinical syndromes have been identified according to the pattern of organ involvement, the type of inflammatory infiltrate in vessels and elsewhere, the size and type of affected vessels, and the presence, absence and specificity of antineutrophil cytoplasmic antibodies (ANCA). ${ }^{3}$ In the absence of a comprehensive understanding of pathogenesis, diagnoses arrived at according to these 
phenomena have proved useful for estimating prognosis, predicting complications and deciding on therapy for individual patients.

As the systemic vasculitides are rare and aetiology is unknown, there has been interest in identifying potential environmental triggers. To this end, two sets of classification criteria of systemic vasculitides were arrived at by consensus among experts (American College of Rheumatology (ACR) and Chapel Hill Consensus Conference (CHCC) ) to be used for epidemiological studies. ${ }^{4-7}$ Although these systems are not commensurate and have been subject to criticism, ${ }^{3,8,9}$ they have formed the basis of numerous studies of epidemiology of the principal forms of PSV. ${ }^{10-25}$ So far, most data have been gathered between 43 and $70^{\circ} \mathrm{N}$ and they suggest that the overall incidence of PSV is similar in different places across this region (approximately 20 cases/million adultsper year). ${ }^{26}$ Analysis of specific syndromes has identified more variation. Furthermore, the limited data available from outside northern Europe and USA suggest that worldwide the incidence might be more heterogeneous. In particular, the reported incidence of classical polyarteritis nodosa (PAN) varies from $77 /$ million in native Alaskans, where hepatitis $\mathrm{B}$ is endemic, to almost absent in the UK. ${ }^{15,27}$ The incidence of microscopic polyangiitis (MPA) also appears to vary according to location. ${ }^{28-30}$ There is evidence to suggest that the incidence of PSV is changing, although increases observed between the 1980s and 1990s could be accounted for by better ascertainment, especially with the development of ANCA as a diagnostic test. ${ }^{10,31}$ Seasonal, regional and familial clustering of cases has been also observed. ${ }^{13,31-34}$ Environmental triggers that have been suggested to account for these findings include infections and exposure to non-pathogenic microorganisms, ultraviolet light exposure and contact with occupational and environmental toxins. ${ }^{24,33,35}$

Overall, estimates of the distribution and incidence of PSV in the southern hemisphere and equatorial regions are relatively scarce and there are no data from Australia. Given the uncertainty regarding possible environmental triggers, obtaining comparative estimates of PSV in these regions is important. We undertook a 10 -year retrospective survey of the epidemiology of PSV in south-eastern Australia, centred on the Australian Capital Territory (ACT). To facilitate comparison between our data with those reported previously from the northern hemisphere, we have used similar strategies for case ascertainment as those applied previously in retrospective studies. Several factors make ACT region amenable to such a survey. First, the region is served by only two teaching hospitals. Second, one laboratory provides ANCA testing for both hospitals. Furthermore, the region comprises a mixture of dense urban settlement and sparse rural population.
Our results suggest that PSV is similarly uncommon in Australia, Europe and the USA and lend some support to the notion that ANCA-associated vasculitides are more common in rural dwellers.

\section{Patients and methods}

Two teaching hospitals within the ACT service, a catchment area that includes the entire ACT, as well as southeastern New South Wales (SE-NSW). SE-NSW regions were included because their demography differs substantially from that of the ACT. Although Canberra Hospital is a tertiary referral centre for an extensive region of SENSW, to reduce the likelihood of underestimating the prevalence because of referrals outside the region, only patients living in either the ACT or the three regions adjacent to the ACT (Queanbeyan, Southern Tablelands and Snowy, as defined by the Australian Bureau of Statistics) were included in the study.

Ethics approval for the project was obtained from institutional ethics review committees of the Canberra and Calvary Hospitals. The clinical databases of inpatients at each hospital were searched for patients fulfilling the World Health Organization International Classification of Disease (ICD) (versions 9 and 10) codes: D89.1 (cryoglobulinaemia), M30.0, M30.1, M30.2, M30.3, M30.8, M31.0, M31.1, M31.2, M31.3, M31.4, M31.8, M31.9 (systemic vasculitides), M 35.2 (Behcet's disease) and I77.6 (arteritis, unspecified). After this, individual records were reviewed independently by two investigators and classifications ascertained according to ACR criteria (Wegener's granulomatosis (WG), PAN, Churg-Strauss syndrome (CSS) or CHCC definitions (MPA). ${ }^{4-7}$ Patients who fulfilled classification criteria for both PAN by ACR criteria and MPA by CHCC were assigned to the MPA category. Patients diagnosed with other forms of vasculitis were excluded from the analysis of PSV. All ANCA requests and results obtained at clinical immunology laboratory servicing these two hospitals between 1 January 1995 and 31 December 2004 were reviewed.

To estimate the prevalence and incidence, denominators were obtained from census data published by the Australian Bureau of Statistics. Census data were available from 1997 and 2003. In 1997, the ACT population was 308 990, of whom $21 \%$ were $<15$ years. By 2003, the ACT population had increased to 322830 ( $18 \%$ were $<15$ years). Census data were also available for each of the three surrounding rural regions of NSW. In all, this population comprised 122209 (22\% were < 15 years) individuals in 1995-2000, and 128507 (22\% were <15 years) in 2001-2005. Five-year period prevalence and annual incidence were calculated according to population size at the mid-point of each interval. For estimation of $95 \%$ 
confidence intervals (CI), incidence and prevalence were assumed to follow the Poisson distribution.

Requests for ANCA are screened by indirect immunofluorescence (IIF) on ethanol-fixed preparations of polymorphonuclear leucocytes. From 1996 onwards, all serum samples found to be positive by IIF were subsequently tested for antibodies to myeloperoxidase (MPO) and proteinase-3 (PR3) by enzyme-linked immunosorbent assay.

\section{Results}

\section{Characteristics of the study group}

The ACT has a total area of 2349.4 sq. $\mathrm{km}$ and is surrounded by NSW. Canberra is the only city in the ACT and is located $150 \mathrm{~km}$ inland, $571 \mathrm{~m}$ a.s.l. at $31^{\circ} \mathrm{S}$. In 2003 , $99.8 \%$ of ACT residents (322 184) lived in the city, where the population density was 135.9 persons/sq. km, one of the highest in Australia. Canberra's population is slightly younger than the national average (Table 1). In contrast to Canberra, the surrounding regions of SE-NSW are sparsely populated rural areas. In 2003, in this region, 125988 individuals lived in a total area of $40840 \mathrm{sq} . \mathrm{km}$, giving an average population density of 3.1 persons/sq. $\mathrm{km}$.

\section{Prevalence and incidence of PSV}

The prevalence of PSV was ascertained by medical record review. First, 438 patients were identified with possible PSV by searching for vasculitis-related disease codes from editions 9 and 10 of the ICD. After review of the case notes, 72 patients of this group met the classification criteria for WG, CSS, PAN or MPA. Neither ACR nor Chapel Hill consensus classification criteria include laboratory data; nevertheless, we surveyed all ANCA results during the study period, first, to corroborate ascertainment by medical record review, and second, to estimate the prevalence and type of ANCA present in patients with PSV in the study group. Between 1 January 1995 and 31 December 2004,

Table 1 Characteristics of the study group

\begin{tabular}{|c|c|c|c|}
\hline & $\begin{array}{c}\text { Australian Capital } \\
\text { Territory }\end{array}$ & $\begin{array}{c}\text { New South } \\
\text { Wales }\end{array}$ & Australia \\
\hline \multicolumn{4}{|l|}{ 1995-1999 } \\
\hline Population (n) & 308990 & 122209 & 18631126 \\
\hline$<15$ years $(\%)$ & 21.0 & 22.0 & 21.0 \\
\hline Median age (years) & 33.9 & 35.5 & 34.4 \\
\hline$M: F$ & 0.976 & 1.1 & 0.99 \\
\hline \multicolumn{4}{|l|}{ 2000-2004 } \\
\hline Population (n) & 322830 & 128507 & 19880599 \\
\hline$<15$ years $(\%)$ & 19.20 & 22.2 & 20.3 \\
\hline Median age (years) & 33.9 & 35.5 & 36.2 \\
\hline$M: F$ & 0.976 & 1.1 & 0.987 \\
\hline
\end{tabular}

5975 ANCA tests were ordered, 130 were positive and medical record review of these yielded 11 additional cases of PSV. Thus, we identified 83 patients who fulfilled the classification criteria for WG, PAN, MPA or CSS, of whom 8 were excluded from further analysis because they resided outside the geographical regions under investigation. Patients who survived beyond the first period contributed to prevalence estimates in both periods (1995-1999, $n=41 ; 2000-2004, n=67$ ). In addition, we identified 40 cases of other forms of vasculitis. To permit comparison with previous studies, these were excluded from the PSV category.

Between 1995 and 1999, the prevalence of PSV was 95/million (95\%CI 76.9-116.1) and this increased to 148/million (95\%CI 125.1-173.9) for the 2000-2004 period. When analysed using the adult population (>14 years) as the denominator (and excluding patients diagnosed when $<15$ years old), the prevalence of PSV was 1 14/million (95\% CI 94.0-140.0) and 184/million (95\% CI 158.4-212.6) for the two successive periods. Although these estimates suggested an increase in PSV during the decade, this conclusion was not supported by incidence estimates, which were similar in both periods (17/year per million adult population (95\%CI 9.9-27.2) for 1995-1999 and 16/year per million adult population (95\%CI 9.2-26.0) for 2000-2004). The median age at diagnosis was 54 years, and men and women were affected equally (men, $n=37$ ) (Fig. 1).

There was a trend towards PSV being more common in rural regions of NSW. In the ACT, the prevalence of PSV was 102/million (95\%CI 83.2-123.8) for 1995-1999 and 155/million (95\%CI 121.6-181.4) for 2000-2004, whereas in SE-NSW, the estimates were $146 /$ million (95\%CI 124.2-172.8) for 1995-1999 and 259/million (95\%CI 228.4-292.5) for 2000-2004 (Table 2).

\section{ANCA-associated vasculitides}

Sixteen patients who fulfilled the CHCC criteria for MPA were identified, giving prevalence estimates of 16/million (95\%CI 9.2-26.0) and 33/million (95\%CI 22.7-46.3) in the first and second periods, respectively or when analysed by adult population, 17.5/million (95\%CI10.7-28.4) and 39.1/million (95\%CI 27.7-53.3) (Table 3). Histological evidence of MPA was present in 14 of 16 patients (renal biopsy, 12of 16; lung biopsy, 3 of 16). Interestingly, seven patients had initially attracted alternative diagnoses (including WG, pauci-immune glomerulonephritis or pulmonary renal syndrome), but review of case notes and histopathology found that they met the classification criteria for MPA. Men accounted for $56 \%$ of cases of MPA. The median age at diagnosis was 63 years, with a range of 6-75 years (Fig. 1). All patients were ANCA positive and 
Table 2 Prevalence and incidence of primary systemic vasculitis in the Australian Capital Territory (ACT) and south-eastern New South Wales (NSW)

\begin{tabular}{lcccc}
\hline & \multicolumn{2}{c}{ Total population } & \multicolumn{2}{c}{ Adult population } \\
& Cases & Per million & Cases & Per million \\
\hline Prevalence & & & & \\
ACT + surrounding NSW & & & \\
\multicolumn{1}{l}{ 1995-1999 } & 41 & 95.1 & 39 & 114.0 \\
2000-2004 & 67 & 148.4 & 66 & 184.4 \\
ACT & & & & \\
1995-1999 & 27 & 87.4 & 25 & 102.4 \\
2000-2004 & 41 & 127.0 & 40 & 155.5 \\
Surrounding NSW & & & & \\
1995-1999 & 14 & 114.6 & 14 & 146.9 \\
2000-2004 & 26 & 202.3 & 26 & 259.4 \\
\hline Incidence (per year) & & & & \\
\hline ACT + surrounding NSW & & & & \\
1995-1999 & 29 & 13.5 & 29 & 17.0 \\
2000-2004 & 31 & 13.7 & 29 & 16.2 \\
ACT & & & & \\
1995-1999 & 19 & 12.3 & 19 & 11.8 \\
2000-2004 & 17 & 10.5 & 16 & 12.4 \\
Surrounding NSW & & & & \\
1995-1999 & 10 & 16.4 & 10 & 21.0 \\
2000-2004 & 14 & 21.8 & 13 & 25.9 \\
\hline
\end{tabular}

15 of 16 of these were specific for MPO, whereas 2 patients had ANCA specific for PR3 (including one with low titres of antibodies to both PR3 and MPO). Interestingly, $56 \%$ of the MPA patients resided in a rural location and there was a difference in the incidence of MPA between rural and urban locations in the period 2000-2004 (rural incidence $14.4(95 \%$ CI 7.7-23.5) and urban incidence 1.6 (95\% CI 0.2-7.2)).

Thirty-eight patients were identified with WG. Men accounted for $44 \%$. The age at diagnosis ranged from 14 to 78 years, with a median age of 55 years. Prevalence in 1995-1999 was 53/million (95\%CI 39.7-69.3) and 78/ million (95\%CI 61.7-97.4) and in the 2000-2004 interval, it was 64/million adult population (95\% CI 49.3-81.7) and 95/million adult population (95\%CI 76.9-1 16.1) (Table 3). The incidence was similar in both periods ( 9 cases/years/ million (95\%CI 4.1-17.1) from 1995 to 1999 and 8 cases/ years/million (95\%CI 3.5-15.8) from 2000 to 2004). There was a trend towards a higher prevalence of WG in the rural population: 1995-1999, 84/million (95\%CI 67.0-104.0) versus 57/million (95\%CI 43.1-73.9); 2000-2004, 129/ million adults $(95 \%$ CI $108.6-154.4)$ versus $82 /$ million adults (95\%CI 65.2-101.8)). Thirty-seven (97\%) of 38 were documented ANCA positive and 27 had antibodies to PR3. Three patients had pANCA, four patients with WG had antibodies to MPO and three patients had

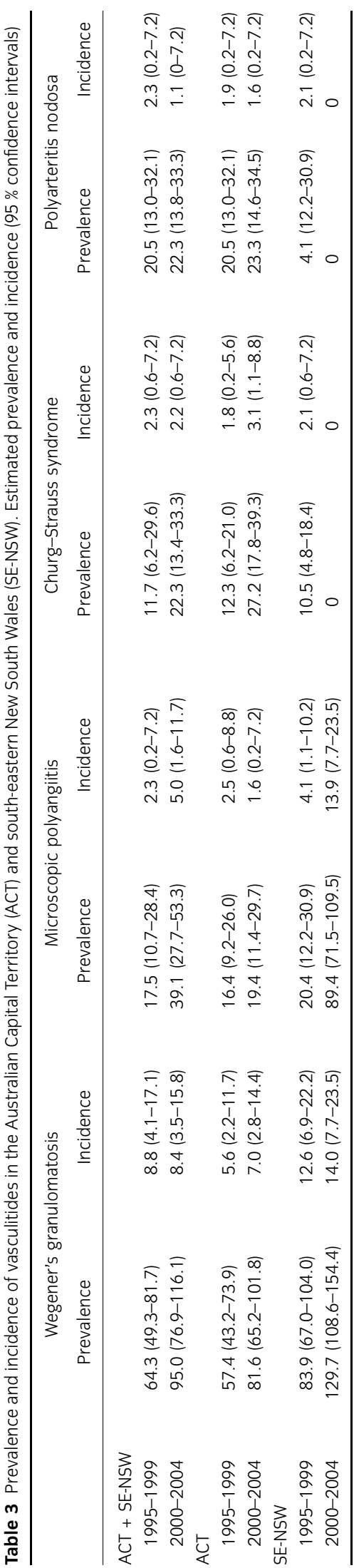

(c) 2008 The Authors

Journal compilation (c) 2008 Royal Australasian College of Physicians 


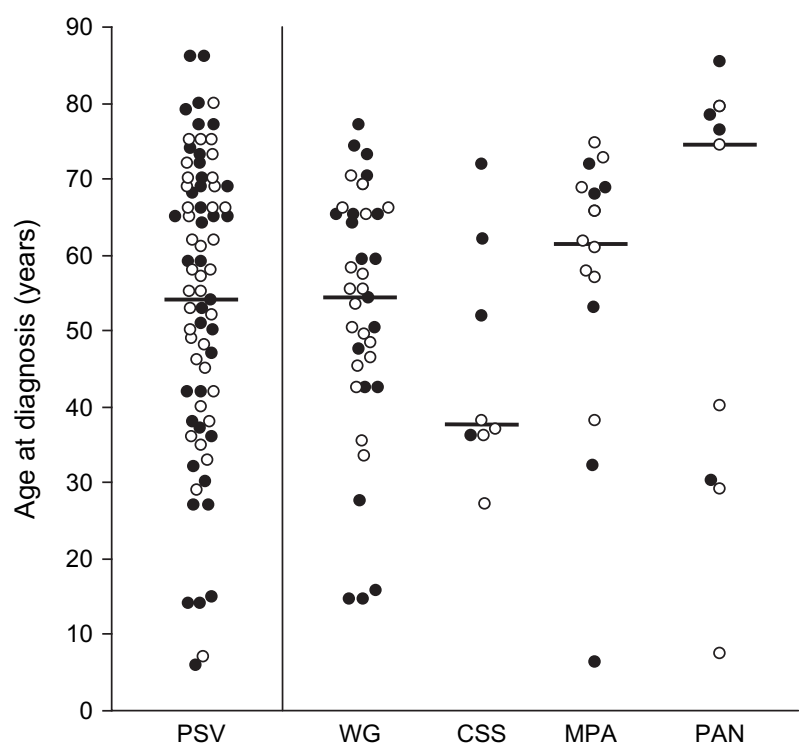

Figure 1 Sex and age at diagnosis for cases of primary systemic vasculitis (PSV) and Wegener's granulomatosis (WG), Churg-Strauss syndrome (CSS), microscopic polyangiitis (MPA) and polyarteritis nodosa (PAN). Bars indicate the median age, open symbols indicate male patients, closed symbols indicate female patients.

atypical or undetermined patterns of IIF. The presence of vasculitis was confirmed by histology in $79.0 \%$ (30 of 38; renal biopsy, 26 of 30; lung biopsy, 5 of 30).

We identified eight patients with CSS. One patient moved out of the region during the study period. Men and women were represented equally. The median age at diagnosis was 38 years (range 27-72 years). Prevalence in 1995-1999 was $9 /$ million $(95 \%$ CI $4.1-17.1)$ and in 2000-2004 it was $18 /$ million (95\%CI 10.7-28.5) and in adults, 11.7/million (95\%CI $6.2-21.0$ ) and $22.3 /$ million (95\% CI 13.8-33.3) (Table 3). Interestingly, only two patients had a positive ANCA at diagnosis. Seven of the eight patients with CSS lived in the city.

\section{Other vasculitides}

Nine patients were identified with PAN $(\mathrm{M}: \mathrm{F}=1)$ and median age at diagnosis was 74 years (range 29-86 years). All nine patients were ANCA negative. Incidence in the first period of study was 2 /million adults $(95 \% \mathrm{CI} 0.2-7.2)$ and $1 /$ million $(95 \% \mathrm{CI} 0.02-5.6)$ in the second period.

In addition, we identified patients with other vasculitides who were not included in the PSV group. Nine patients were identified with Behcet's disease (30\% men). Eight were born in Australia and the last one was from Tonga. Incidence was $0.6 /$ million per year $(95 \% \mathrm{CI} 0.03-3.7)$ during 1995-1999 and 3.4/million per year (95\%CI $1.1-8.8)$ between 2000 and 2004. Finally, we identified 20 patients with Kawasaki disease. Median age at diagnosis was 3 years (range $<1-8$ years). Twenty-one $(95 \%)$ were born in Australia and the last in Korea. Incidence was 11.2/ million children per year (95\% CI 6.2-19.7) and 30/million children per year $(95 \%$ CI $20.2-42.8)$ during the two successive periods.

\section{Discussion}

These data, obtained from a population comprising both rural and urban dwellers and located in the southern hemisphere, but equatorial to locations of comparable northern hemisphere surveys, show overall similarities in the prevalence and incidence of PSV to those reported previously (Table 4). ${ }^{10-24}$ During the first 5 years of our study (1995-1999), the prevalence of PSV was 1 14/million adult population and 184/million during the second period. PSV was most common in individuals in their sixth decade and men and women were similarly affected. The

Table 4 Summary of the incidence of primary systemic vasculitides in the Australian Capital Territory (ACT) and elsewhere

\begin{tabular}{|c|c|c|c|c|c|c|c|c|}
\hline Place & Period & PSV & WG & MPA & CSS & PAN & Latitude & Reference \\
\hline \multirow[t]{2}{*}{ ACT (adults) ${ }^{\dagger}$} & 1995-1999 & 17.0 & 8.8 & 2.3 & 2.3 & 2.3 & \multirow[t]{2}{*}{$35-36^{\circ} \mathrm{S}$} & \\
\hline & 2000-2004 & 16.2 & 8.4 & 5.0 & 2.2 & 1.1 & & \\
\hline Lugo, Spain ${ }^{\dagger}$ & 1988-1994 & 13.01 & 2.95 & 7.91 & 1.31 & 0.9 & $43^{\circ} \mathrm{N}$ & 19 \\
\hline Bath/Bristol $^{\dagger}$ & $1972-80$ & & 0.5 & & & 4.6 & $51.5^{\circ} \mathrm{N}$ & 36 \\
\hline \multirow[t]{2}{*}{ Norwich, UK ${ }^{\ddagger}$} & 1988-1997 & 22.4 & 9.7 & 8.0 & 2.7 & 8.0 & $52^{\circ} \mathrm{N}$ & 15 \\
\hline & 1988-1998 & 18.9 & 10.6 & 8.4 & 3.1 & $0(\mathrm{CHCC})$ & $52^{\circ} \mathrm{N}$ & \multirow{3}{*}{10} \\
\hline \multirow[t]{2}{*}{ Leicester, $\mathrm{UK}^{\dagger}$} & 1980-1986 & & 0.7 & 0.5 & & & \multirow[t]{2}{*}{$52.5^{\circ} \mathrm{N}$} & \\
\hline & 1987-1989 & & 2.9 & 3.0 & & & & \\
\hline Schleswig-Holstein, Germany ${ }^{\ddagger}$ & 1998 & & $6-12$ & 3 & 1 & $0.4-1.0$ & $54.3^{\circ} \mathrm{N}$ & 18 \\
\hline Vilnius, Lithuania ${ }^{\dagger, \ddagger}$ & 1990-1999 & & 2.1 & 3 & 1.3 & 7.7 & $54.4^{\circ} \mathrm{N}$ & 23 \\
\hline Kristiansand, Norway ${ }^{\dagger}$ & 1992-1996 & & 6.6 & & & 6.6 & $58^{\circ} \mathrm{N}$ & 12 \\
\hline Tromsø, Norway ${ }^{\dagger}$ & 1988-1998 & 13.7 & $9.3-10.5$ & 2.7 & 0.5 & 0.5 (CHCC) & $70^{\circ} \mathrm{N}$ & 17 \\
\hline
\end{tabular}

${ }^{\dagger}$ Retrospective cohort. ${ }^{\ddagger}$ Prospective cohort. CSS, Churg-Strauss syndrome; MPA, microscopic polyangiitis; PAN, polyarteritis nodosa; PSV, primary systemic vasculitides; WG, Wegener's granulomatosis. 
incidence was approximately $17 /$ million adult population per year throughout the decade, which is similar to the estimated incidence of $20 /$ million reported by Watts et al., who reviewed evidence from all northern hemisphere surveys. $^{26}$

Although there is some evidence from previous studies to suggest that the incidence of PSV is increasing, ${ }^{17,26,28,31}$ this has not been a consistent finding. ${ }^{19,22}$ One explanation for an increase in incidence is the discovery of ANCA and widespread recognition of their diagnostic value for some forms of PSV. ${ }^{31}$ Our study shows that during the decade beginning in 1995, there was no significant change in incidence. The ANCA test was available throughout this period and our data indicate that test was used in the vast majority of the patients. We therefore cannot draw any conclusions from this dataset about whether the advent of ANCA testing influenced the incidence of PSV.

Variation in the incidence of PSV, or some subsets of vasculitis, according to latitude could provide clues to environmental triggers. This is a plausible hypothesis because other immune-related pathologies have been shown to have a latitudinal gradient of incidence. ${ }^{37,38}$ Although giant cell arteritis appears to be more prevalent in Scandinavia compared with Spain, overall, the evidence for a latitudinal gradient in systemic vasculitis is weak. ${ }^{39}$ Studies in the Northern hemisphere have included patients from $70^{\circ} \mathrm{N}$ (Tromsø, Norway) ${ }^{17}$ to $43^{\circ} \mathrm{N}$ (Lugo, Spain), ${ }^{19}$ but have not shown consistent differences in PSV incidence. There appears to be a high level of consistency in the overall prevalence of PSV from different parts of the globe, from which and our data do not deviate. The ACT and surrounding NSW is located at $31^{\circ} \mathrm{S}$ and we found no evidence that the prevalence is significantly different here from Tromsø (13.7 vs 16/million). ${ }^{17}$

In contrast to the consistency of estimates for prevalence of all forms of PSV, prevalence of specific vasculitic syndromes does appear to vary with location. A trivial explanation is differences in awareness of these rare diseases. A more significant problem is accuracy of classification criteria and their application so that variations in estimates of prevalence may not indicate real differences. ${ }^{9}$ In particular, the incidence of MPA has been shown to vary in previous studies, ${ }^{28,29}$ which might be in part due to differences in diagnostic criteria. ${ }^{40}$ Had our estimate of MPA been based on the clinical diagnosis, we would have significantly underestimated the prevalence of this disease. MPA was estimated to affect 7.9/million adultsper year in northern Spain and a similar number in Norwich, whereas in the ACT, MPA affects only 2-4/million per year. ${ }^{17,25}$ WG appears to be more common in northern than in southern Europe. ${ }^{17,25}$ There is evidence from New Zealand to suggest a latitudinal gradient for WG. ${ }^{24,41}$ In our population, the incidence of WG was $6-7 /$ million per year during the decade of study. This is higher than the incidence in northern Spain 2.95 (95\% CI 1.44-6.05), but slightly lower than that in England and in Norway. ${ }^{17,19}$ Variation in estimates of prevalence could also be attributed to differences in study design, especially with regard to case detection. Prospective studies have tended to arrive at higher prevalence estimates. ${ }^{15,18}$ Other explanations for variations include the failure to ascertain those managed as outpatients, or referred elsewhere for treatment, which would result in an underestimate of the prevalence.

Another outstanding question is whether the prevalence of PSV is different in rural and urban areas. In New York State, the prevalence varied from county to county, although there was no clear correlation to urban or rural environments, ${ }^{10}$ whereas PSV was more common in urban areas in Germany and CSS was more common in rural Norfolk. ${ }^{22,39}$ Our study group is well suited to address this question because the ACT is a densely populated urban environment, situated within a vast area of rural Australia. Although the rarity of PSV makes this question difficult to answer with confidence, especially in a study sample of this size, we found PSV, WG and MPA to be more common in the rural regions.

In conclusion, our results are consistent with a similar incidence of PSV in different westernized countries irrespective of latitude. However, our data lend support to the suggestion that ANCA-associated vasculitides, especially WG and MPA, are more common in rural than urban environments. If this trend were real, it would support a role for triggers dependent on local ecology, such as human contact with specific microorganisms, rather than those that vary globally, such as sunlight exposure. However, our findings would also be consistent with the conclusion that the incidence of these rare diseases is stochastic and unlikely to be attributed, at least at a population level, to any recognizable gene-environment combination.

\section{Acknowledgements}

The authors would like to thank Gloria Spyropoulos and Denise Crowe from the medical record departments at Canberra and Calvary Hospitals, Australian Capital Territory, for assistance in retrieving patient data.

\section{References}

1 Lapraik C, Watts R, Scott DG. Modern management of primary systemic vasculitis. Clin Med 2007; 7: 43-7.

2 Lane SE, Watts RA, Shepstone L, Scott DG. Primary systemic vasculitis: clinical features and mortality. QJM 2005; 98: 97-111. 
3 Jennette JC, Falk RJ. Nosology of primary vasculitis. Curr Opin Rheumatol 2007; 19: 10-16.

4 Leavitt RY, Fauci AS, Bloch DA, Michel BA, Hunder GG, Arend WP et al. The American College of Rheumatology 1990 criteria for the classification of Wegener's granulomatosis. Arthritis Rheum 1990; 33: 1101-7.

5 Lightfoot RW Jr, Michel BA, Bloch DA, Hunder GG, Zvaifler NJ, McShane DJ et al. The American College of Rheumatology 1990 criteria for the classification of polyarteritis nodosa. Arthritis Rheum 1990; 33: 1088-93.

6 Masi AT, Hunder GG, Lie JT, Michel BA, Bloch DA, Arend WP et al. The American College of Rheumatology 1990 criteria for the classification of Churg-Strauss syndrome (allergic granulomatosis and angiitis). Arthritis Rheum 1990; 33: 1094-100.

7 Jennette JC, Falk RJ, Andrassy K, Bacon PA, Churg J, Gross WL et al. Nomenclature of systemic vasculitides. Proposal of an international consensus conference. Arthritis Rheum 1994; 37: 187-92.

8 Lie JT. Nomenclature and classification of vasculitis: plus ca change, plus c'est la meme chose. Arthritis Rheum 1994; 37: 181-6.

9 Watts R, Lane S, Hanslik T, Hauser T, Hellmich B, Koldingsnes $\mathrm{W}$ et al. Development and validation of a consensus methodology for the classification of the ANCA-associated vasculitides and polyarteritis nodosa for epidemiological studies. Ann Rheum Dis 2007; 66: 222-7.

10 Andrews M, Edmunds M, Campbell A, Walls J, Feehally J. Systemic vasculitis in the 1980s-is there an increasing incidence of Wegener's granulomatosis and microscopic polyarteritis? J R Coll Physicians Lond 1990; 24: 284-8.

11 Cotch MF, Hoffman GS, Yerg DE, Kaufman GI, Targonski P, Kaslow RA. The epidemiology of Wegener's granulomatosis. Estimates of the five-year period prevalence, annual mortality, and geographic disease distribution from population-based data sources. Arthritis Rheum 1996; 39: 87-92.

12 Haugeberg G, Bie R, Bendvold A, Larsen AS, Johnsen V. Primary vasculitis in a Norwegian community hospital: a retrospective study. Clin Rheumatol 1998; 17: 364-8.

13 Tidman M, Olander R, Svalander C, Danielsson D. Patients hospitalized because of small vessel vasculitides with renal involvement in the period 1975-95: organ involvement, anti-neutrophil cytoplasmic antibodies patterns, seasonal attack rates and fluctuation of annual frequencies. $J$ Intern Med 1998; 244: 133-41.

14 Gonzalez-Gay MA, Garcia-Porrua C. Systemic vasculitis in adults in northwestern Spain, 1988-1997. Clinical and epidemiologic aspects. Medicine (Baltimore) 1999; 78: 292-308.

15 Watts RA, Lane SE, Bentham G, Scott DG. Epidemiology of systemic vasculitis: a ten-year study in the United Kingdom. Arthritis Rheum 2000; 43: 414-9.

16 Watts RA, Gonzalez-Gay MA, Lane SE, Garcia-Porrua C, Bentham G, Scott DG. Geoepidemiology of systemic vasculitis: comparison of the incidence in two regions of Europe. Ann Rheum Dis 2001; 60: 170-72.

17 Koldingsnes W, Nossent H. Epidemiology of Wegener's granulomatosis in northern Norway. Arthritis Rheum 2000; 43: 2481-7.

18 Reinhold-Keller E, Herlyn K, Wagner-Bastmeyer R, Gutfleisch J, Peter HH, Raspe HH et al. No difference in the incidences of vasculitides between north and south Germany: first results of the German vasculitis register. Rheumatology (Oxford) 2002; 41: 540-49.

19 Gonzalez-Gay MA, Garcia-Porrua C, Guerrero J, Rodriguez-Ledo P, Llorca J. The epidemiology of the primary systemic vasculitides in northwest Spain: implications of the Chapel Hill Consensus Conference definitions. Arthritis Rheum 2003; 49: 388-93.

20 Dolezalova P, Telekesova P, Nemcova D, Hoza J. Incidence of vasculitis in children in the Czech Republic: 2-year prospective epidemiology survey. $J$ Rheumatol 2004; 31: 2295-9.

21 Mahr A, Guillevin L, Poissonnet M, Ayme S. Prevalences of polyarteritis nodosa, microscopic polyangiitis, Wegener's granulomatosis, and Churg-Strauss syndrome in a French urban multiethnic population in 2000: a capture-recapture estimate. Arthritis Rheum 2004; 51: 92-9.

22 Reinhold-Keller E, Herlyn K, Wagner-Bastmeyer R, Gross WL. Stable incidence of primary systemic vasculitides over five years: results from the German vasculitis register. Arthritis Rheum 2005; 53: 93-9.

23 Dadoniene J, Kirdaite G, Mackiewicz Z, Rimkevicius A, Haugeberg G. Incidence of primary systemic vasculitides in Vilnius: a university hospital population based study. Ann Rheum Dis 2005; 64: 335-6.

24 Gibson A, Stamp LK, Chapman PT, O'Donnell JL. The epidemiology of Wegener's granulomatosis and microscopic polyangiitis in a Southern Hemisphere region. Rheumatology (Oxford) 2006; 45: 624-8.

25 Mohammad AJ, Jacobsson LT, Mahr AD, Sturfelt G, Segelmark M. Prevalence of Wegener's granulomatosis, microscopic polyangiitis, polyarteritis nodosa and Churg-Strauss syndrome within a defined population in southern Sweden. Rheumatology (Oxford) 2007; 46: 1329-37.

26 Watts RA, Lane S, Scott DG. What is known about the epidemiology of the vasculitides? Best Pract Res Clin Rheumatol 2005; 19: 191-207.

27 McMahon BJ, Heyward WL, Templin DW, Clement D, Lanier AP. Hepatitis B-associated polyarteritis nodosa in Alaskan Eskimos: clinical and epidemiologic features and long-term follow-up. Hepatology 1989; 9: 97-101.

28 Sanchez-Torres AA, Acedevo-Vasquez EM, Sanchez-Schwartz CG, Pastor-Asurza CA, Perich-Campos RA, Alfaro-Lozano JL et al. Epidemiology of primary systemic vasculitis in a Latin American population. In: 13th International vasculitis and ANCA workshop; 2007; Cancun, Mexico. Clin Exp Rheumatol 2007; 25 Suppl. 44: 595. 
29 el-Reshaid K, Kapoor MM, el-Reshaid W, Madda JP, Varro J. The spectrum of renal disease associated with microscopic polyangiitis and classic polyarteritis nodosa in Kuwait. Nephrol Dial Transplant 1997; 12: 1874-82.

30 Lane SE, Scott DG, Heaton A, Watts RA. Primary renal vasculitis in Norfolk-increasing incidence or increasing recognition? Nephrol Dial Transplant 2000; 15: 23-7.

31 Carruthers DM, Watts RA, Symmons DP, Scott DG. Wegener's granulomatosis-increased incidence or increased recognition? Br J Rheumatol 1996; 35: 142-5.

32 Fietta P. Systemic vasculitides: immunogenetics and familial clustering. Clin Exp Rheumatol 2004; 22: 238-51.

33 Albert DA, Albert AN, Vernace M, Sebastian JK, Hsia EC. Analysis of a cluster of cases of Wegener granulomatosis. J Clin Rheumatol 2005; 11: 188-93.

34 Rottem M, Cotch MF, Fauci AS, Hoffman GS. Familial vasculitis: report of 2 families. J Rheumatol 1994; 21: 561-3.

35 Lane SE, Watts RA, Bentham G, Innes NJ, Scott DG. Are environmental factors important in primary systemic vasculitis? A case-control study. Arthritis Rheum 2003; 48: 814-23.
36 Scott DG, Bacon PA, Elliott PJ, Tribe CR, Wallington TB. Systemic vasculitis in a district general hospital 1972-1980: clinical and laboratory features, classification and prognosis of 80 cases. Q J Med 1982; 51: 292-311.

37 Kurtzke JF. Geography in multiple sclerosis. J Neurol 1977; 215: 1-26.

38 Nystrom L, Dahlquist G, Ostman J, Wall S, Arnqvist H, Blohme $\mathrm{G}$ et al. Risk of developing insulin-dependent diabetes mellitus (IDDM) before 35 years of age: indications of climatological determinants for age at onset. Int $J$ Epidemiol 1992; 21: 352-8.

39 Scott DG, Watts RA. Systemic vasculitis: epidemiology, classification and environmental factors. Ann Rheum Dis 2000; 59: 161-3.

40 Bruce IN, Bell AL. Effect of classification on the incidence of polyarteritis nodosa and microscopic polyangiitis: comment on the article by Watts et al. Arthritis Rheum 1997; 40: 1183.

41 O'Donnell JL, Stevanovic VR, Frampton C, Stamp LK, Chapman PT. Wegener's granulomatosis in New Zealand: evidence for a latitude-dependent incidence gradient. Intern Med J 2007; 37: 242-6. 